\title{
PGASO: A synthetic biology tool for engineering a cellulolytic yeast
}

\author{
Jui-Jen Chang ${ }^{1,2}$, Cheng-Yu Ho ${ }^{3,4}$, Feng-Ju Ho ${ }^{1}$, Tsung-Yu Tsai ${ }^{1}$, Huei-Mien Ke ${ }^{1,5}$, Christine H-T Wang ${ }^{1}$, \\ Hsin-Liang Chen ${ }^{1}$, Ming-Che Shih ${ }^{6^{*}}$, Chieh-Chen Huang ${ }^{3,4^{*}}$ and Wen-Hsiung $\mathrm{Li}^{1,2,7^{*}}$
}

\begin{abstract}
Background: To achieve an economical cellulosic ethanol production, a host that can do both cellulosic saccharification and ethanol fermentation is desirable. However, to engineer a non-cellulolytic yeast to be such a host requires synthetic biology techniques to transform multiple enzyme genes into its genome.

Results: A technique, named Promoter-based Gene Assembly and Simultaneous Overexpression (PGASO), that employs overlapping oligonucleotides for recombinatorial assembly of gene cassettes with individual promoters, was developed. PGASO was applied to engineer Kluyveromycesmarxianus KY3, which is a thermo- and toxin-tolerant yeast. We obtained a recombinant strain, called KR5, that is capable of simultaneously expressing exoglucanase and endoglucanase (both of Trichodermareesei), a beta-glucosidase (from a cow rumen fungus), a neomycin phosphotransferase, and a green fluorescent protein. High transformation efficiency and accuracy were achieved as $\sim 63 \%$ of the transformants was confirmed to be correct. KR5 can utilize beta-glycan, cellobiose or CMC as the sole carbon source for growth and can directly convert cellobiose and beta-glycan to ethanol.

Conclusions: This study provides the first example of multi-gene assembly in a single step in a yeast species other than Saccharomyces cerevisiae. We successfully engineered a yeast host with a five-gene cassette assembly and the new host is capable of co-expressing three types of cellulase genes. Our study shows that PGASO is an efficient tool for simultaneous expression of multiple enzymes in the kefir yeast KY3 and that KY3 can serve as a host for developing synthetic biology tools.
\end{abstract}

Keywords: Consolidated bioprocess, Synthetic biology, Yeast, Cellulolytic enzymes, Bio-ethanol

\section{Background}

Among the current approaches to cellulosic ethanol production, consolidated bioprocessing (CBP) is most preferred because of its simplicity and potential low cost [1]. To achieve CBP, a microbe that can carry out cellulase production, hydrolysis, and fermentation in a single process is needed. Currently, however, there is no single microbe available for doing CBP efficiently. Although Saccharomyces cerevisiae has been considered the best ethanol producer from hexose sugars, its genome lacks genes for cellulolytic enzymes. Thus, there

\footnotetext{
*Correspondence: mcshih@gate.sinica.edu.tw; cchuang@nchu.edu.tw; whli@ sinica.edu.tw

${ }^{6}$ Agricultural Biotechnology Research Center, Academia Sinica, Taipei 115, Taiwan

${ }^{3}$ Department of Life Sciences, National Chung Hsing University, Taichung 402, Taiwan

${ }^{1}$ Biodiversity Research Center, Academia Sinica, Taipei 115, Taiwan

Full list of author information is available at the end of the article
}

have been efforts to introduce cellulase genes into $S$. cerevisiae $[2,3]$. Previously, we made attempts to improve the signal peptide for secretion or to reduce the glycosylation strength of $S$. cerevisiae, so that we could over-express cellulase genes of other fungi in $S$. cerevisiae. Unfortunately, most of the expressed proteins were either non-functional or could not be efficiently secreted out of the cell (data not shown). Recently, we isolated a kefir yeast, Kluyveromyces marxianus KY3 (data not shown), that has the potential to serve as a host for bioethanol production and a biorefinery platform, because the strain has broad substrate spectrum, including both hexose and pentose sugars, and produce valuable flavor byproducts such as 2-phenylethanol. The strain also shows resistant to inhibitors generated from chemical pretreatment of lignocellulose and is heattolerant $[4,5]$. Moreover, many genetic and genomic
C Biomed Central

(c) 2012 Chang et al.; licensee BioMed Central Ltd. This is an Open Access article distributed under the terms of the Creative Commons Attribution License (http://creativecommons.org/licenses/by/2.0), which permits unrestricted use, distribution, and reproduction in any medium, provided the original work is properly cited. 
tools such as those developed for $K$. lactis [6,7] are applicable to KY3.

Recently, synthetic biology has been recognized as a powerful approach for the design and construction of new biological systems. Although cloning tools such as the Univector plasmid-fusion system [8], ligase-free [9] or ligation-independent cloning (LIC) [10], and the Gateway cloning system [11,12] have been developed and widely adopted, a technique that can assemble multiple genes in a desired order in a single step and integrate the large DNA piece into a genome is highly desirable. To achieve this goal, various techniques have been developed to enable the assembly of several genes or DNA modules into a larger construct, including chain reaction cloning [13], the OGAB method [14], DNA assembler in vivo [15], USER cloning [16], MAGIC [17], SLIC [18], In-Fusion Clontech [19], Illegitimate recombination [20], Circular polymerase extension cloning [21], and one-step assembly in yeast [22,23]. These methodologies are based mainly on historically wellcharacterized hosts, such as Escherichia coli, Bacillus subtilis and S. cerevisiae, whereas newly discovered organisms with great characteristics for bioprocessing are still in need of synthetic biology tools.

The synthetic biology technique we developed in this study relies on homologous recombination, which is responsible for a number of important transformation processes of microorganisms and is very useful for the generation of host cells for both cloning and expression of heterologous genes. Several transformation systems have been developed for use with S. cerevisiae by episomal plasmids and integrating plasmids with foreign DNA fragments $[15,24,25]$. In a previous study, an extending homologous recombination approach was demonstrated by assembling a megaplasmid from multiple overlapping fragments in a single step in S. cerevisiae [22]. Moreover, episomal plasmid and integrating plasmid transformation studies on other yeast species, such as $K$. lactis, have also been reported $[6,7,26]$. Although non-homologous end-joining (NHEJ) is a common phenomenon in fungi and serves as a transformation method in K. marxianus [20,27], the homologous recombination strategy has several advantages for genetic engineering in fungi, such as ordered multiple gene assembly in one step $[22,23]$. Compared to NHEJ, this strategy is simpler for controlling the copy numbers of interested genes in a genome, and for targeting specific genes for insertion or disruption.

The technique we developed is called "Promoter-based Gene Assembly and Simultaneous Overexpression (PGASO)". PGASO has four advantages for genome engineering: (1) Multiple genes can be transformed into a genome in a single step; (2) specific upstream promoter sequences can be used in the gene assembly in a predesignated order without linker sequence; (3) each gene cassette has a unique promoter, so that its expression level can be adjusted; and (4) PGASO can be applied to a host that can undergo homologous recombination. As an example of application, we applied PGASO to integrate five gene cassettes in a predesignated order into a specific site in the genome of $K$. marxianus KY3 in a single step. The five genes include one reporter gene, one selectable marker gene, and three different essential cellulase genes for cellulose saccharification. The purpose of this construct is to engineer $K$. marxianus KY3 into a host for cellulose saccharification and ethanol fermentation in one step. This is the first example of multi-gene assembly in a yeast species other than S. cerevisiae.

\section{Results and discussion}

\section{The technical concept}

We developed the Promoter-based Gene Assembly and Simultaneous Overexpression (PGASO) technique to insert multiple gene cassettes in a predesignated order into the genome of a cell. Each gene cassette contains 2 parts: (1) the gene sequence linked, at the 5 ' end, to a promoter sequence, and (2) a sequence at the 3' end of the gene cassette that is identical to the $5^{\prime}$ end of the adjacent cassette (Figure 1). A portion of the 5' end of the promoter sequence for the first gene cassette and a portion of the 3' end of the last gene cassette are homologous to a predetermined site in the host genome in order to facilitate site-specific insertion. The promoter sequence in a gene cassette should be different from that of all other gene cassettes. The sequence at the 3' end of a gene cassette, however, should be homologous to a portion of the promoter sequence in the adjacent downstream gene cassette. When the gene cassettes are introduced into the cells, they join together in the predesignated order via homologous recombination between the pairs of overlapping and promoter sequences, and they are inserted into the genome via homologous recombination at the promoter sequence of the first and the 3' end of the last gene cassette. To examine the insertion probability of a non-specific gene fragment in our experiment, the single KanMX gene cassette (kan) that possessed a single homologous recombination site in the $K$. marxianus KY3 genome was transformed into the host. The same molar ratio of a positive control vector with the KanMX gene that possessed two recombination sites in the KY3 genome was also transformed as the control strain (NC). The transformation efficiencies of kan and $\mathrm{NC}$ were calculated by counting the colonies on the plates with G418, and the ratio was 1:93. This benchmark test showed the potential of transformation via homologous recombination in $K$. marxianus KY3. In this study, our use of the specific 5 -upstream region of 


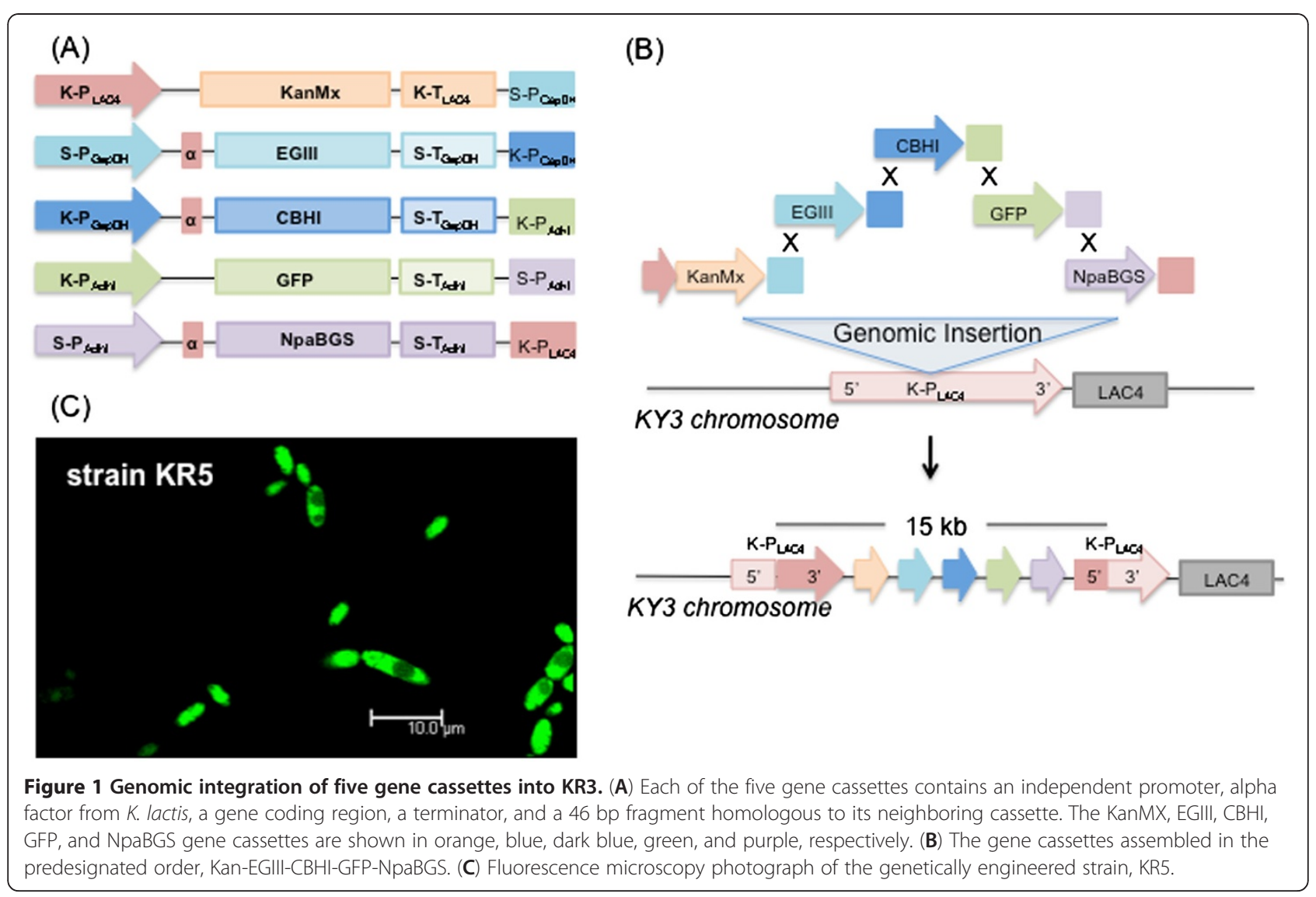

the promoter as the specific homologous recombination sites, requiring no linkers, is the first such application in a yeast other than $S$. cerevisiae. PGASO is potentially applicable to any host that can undergo homologous recombination.

\section{Insertion of five gene cassettes}

To confer the hydrolysis ability of $K$. marxianus KY3 on higher order carbon sources such as cellulose, three cellulase genes, a selection marker gene and a reporter gene were introduced into the KY3 genome. The three cellulase genes were a beta-glucosidase gene (NpaBGS), originally found in a cow rumen fungus [28], and two $T$. reeseicellulase genes (i.e., an endo-glucanase gene (EGIII) and an exo-glucanase gene (CBHI)). The neomycin phosphotransferase gene essential for G418 resistance (Kan MX) was used as a marker gene for clone screening. The green fluorescent protein (GFP) gene was employed as a promoter reporting system and as a biosensor to monitor cell state; this gene can be readily replaced by a cellulase gene to increase the glucanase activity. The five genes were assembled as one single cassette for genetic manipulation via recombinatorial insertion. To reduce unexpected recombination events in multi-gene integration into similar regions, various unique heterologous promoters were used. To express these cellulases in the same culture for multiple enzyme reactions, several constitutive promoters were chosen for the gene cassettes. These promoters included GapDH (ScPGapDH) and ADHI (ScPADHI) from S. cerevisiae and Lac4 (PLac4), GapDH (KlPGapDH) and ADHI (KIPADHI) from $K$. lactis, which showed only 40$55 \%$ sequence identity among each other in the 5 ' upstream regions.

We achieved the transformation of five gene cassettes in a single step into the genome of $K$. marxianus KY3 using the PGASO method. The order and composition of the resulting single five-gene cassette was as follows. The first gene was a selection marker gene (the KanMX gene, $810 \mathrm{bp}$ ) linked with a portion of PLac4 promoter. The second gene, an endoglucanase gene (the EGIII gene, $1449 \mathrm{bp})$, was linked with the KlPGapDH promoter. The third gene, an exoglucanase gene (the CBHI gene, $1749 \mathrm{bp}$ ), was driven by the KlPGapDH promoter. The fourth gene contained a reporter gene (the GFP gene, $720 \mathrm{bp}$ ) and was driven by the ScPADHI promoter. The last gene, a beta-glucosidase gene (the NpaBGS gene, $2526 \mathrm{bp}$ ), was linked with the KIPADHI promoter. These five gene cassettes were prepared by PCR, with a 46 bp overhanging sequence to the $5^{\prime}$ end of each 
promoter and a 46 bp overhanging sequence to the 3' end of the terminator region (Figure 1A). The overhangs were designed to facilitate homologous recombination, because the 5' end of each fragment overlaps with the 3' end of its 5' upstream neighbor; the 5' overhang of the first cassette (the KanMX gene) and the 3' terminal on the last cassette (the NpaBGS gene) overlap with the Lac4 promoter region in K. marxianus KY3 (Figure 1B). Consequently, the five gene cassettes, each with an independent promoter, alpha factor from $K$. lactis, gene coding region, and terminator, were assembled in the designed order as "Kan-EGIII-CBHI-GFP-NpaBGS" with a total DNA fragment length of $14,877 \mathrm{bp}$, which was then integrated into the Lac4 promoter region of $K$. marxianus KY3 via a single-step genome recombination (Figure 1B). A transformed strain, the $K$. marxianus KR5 strain, was selected with G418 resistance; the activation of green fluorescent protein via promoter ScPADHI was confirmed by fluorescence microscopy (Figure 1C).

The five-gene insertion in KR5 was confirmed by PCR using five pairs of gene-specific internal primers (Table 1); the PCR products could be resolved in five specific bands (Figure 2A). The multi-gene transformation efficiency of the KY3 host is high, as all the selected 48 colonies had the five heterologous gene cassettes. The transformation efficiencies of the benchmarks, kan and NC, and KR5, were calculated by counting the colonies on the G418 plates, and their ratio was 1:93:24. To verify that these gene cassettes were assembled in the correct order, five internal primer pairs spanning the gap regions of each cassette were designed (Table 1). The PCR products showed in five specific bands, L-K, K-E, E-C, C-G, G-N, and N-L with correct sizes, $2400 \mathrm{bp}, 2293 \mathrm{bp}, 1712 \mathrm{bp}, 2273 \mathrm{bp}$, $1905 \mathrm{bp}$, and $2575 \mathrm{bp}$, respectively (Figure 2B). The onestep multi-gene fragment assembly method has thus been successfully demonstrated in KR5. The accuracy of assembly was also high, as an average of $62.5 \%$ colonies were found to have a five gene cassettes assembly with the predesigned order. To determine the relative copy number of these five genes in KR5, the genomic DNA was isolated from KR5 and from the control strain NC for quantitative PCR analysis, using the 5 gene-specific primer sets (Table 1). The ratios of the inserted copy-numbers of the five genes in the constructed KR5 isolates relative to the indigenous alg9 gene were approximately 1.7 (kan), 1.2 (egIII), 2.3 (cbhI), 0.9 (gfp) and 6.2 (npabgs) (Figure 2C). Although the probability of non-specific insertion was not high, these data suggested that the unequal gene copy numbers might be caused by non-specific gene insertions or incomplete gene cassette assembly. Similar results were obtained using the indigenous actin gene as the reference gene (data not shown).

Our study shows that assembling specific sequences using overlapping fragments [22] is feasible and that
PGASO can be tailored for various purposes via promoter design. Although we obtained a transformant (KR5) with the specified order of gene cassettes, the strain also contained some unexpected insertions resulting from the NHEJ pathway [20], especially the last gene cassettes. To increase the gene targeting insertion in the yeast genome, longer recombination fragments were employed at the border of the first and the last gene cassette. In transformants, a higher number of copies was found in both the first and the last gene cassette. These unanticipated insertions could be avoided by reducing the NHEJ effect. To reduce NHEJ, we note that inhibition of the DNA double-strand break (DSB) repair system was found to hinder the random gene integration process, resulting in a higher gene targeting efficiency by homologous DNA [27]. This may the next step to improve our PGASO system.

\section{Expression of the five heterologous promoters}

To analyze the gene expression profiles of the five heterologous promoters in KR5, KR5 cells were incubated at $30^{\circ} \mathrm{C}, 37^{\circ} \mathrm{C}, 40^{\circ} \mathrm{C}$, and $42^{\circ} \mathrm{C}$. Total RNA under each of these conditions was isolated from KR5 for quantitative PCR analysis, and alg9 was employed as the reference gene. After normalizing by the inserted gene copynumber, the expression levels of the five promoters, expressed as a multiple of alg9 expression, were 97.2 (PLac4), 4.8 (ScPGapDH), 1.7 (KlPGapDH), 11.4 (KlPADHI) and 38.8 (ScPADHI) at $30^{\circ} \mathrm{C}$ (Fig. 3). These data indicated that the PLac4 and ScPADHI promoters were stronger than the ScPGapDH, KIPGapDH, and KIPADHI promoters in KR5 in all of the experimental conditions used. When the incubation temperature of KR5 was raised to $37^{\circ} \mathrm{C}$ and $40^{\circ} \mathrm{C}$, the expression level of PLac4, ScPGapDH and ScPADHI were simultaneously raised. On the other hand, incubation at $42^{\circ} \mathrm{C}$ was not a favorable condition for the expression of all five heterologous promoters in KR5. The transcription profiles revealed that $40^{\circ} \mathrm{C}$ might be an optimal gene expression condition for the KR5 system using these five promoters.

These observations also indicate unequal gene copy numbers and transcript abundances among the five genes. These inequalities might have been caused by both non-specific gene insertions and differences in transcriptional efficiency among the promoters. A comparison of transcript abundances suggests that in KR5 the GapDH and AdhI promoters from K. lactis are inherently weaker and the AdhI promoter from S. cerevisiae is stronger than the other constitutive promoters used in this study. All regulatory elements (promoters) used here were derived from strong constitutive genes associated with yeast-specific metabolic pathways. The use of this type of promoter is advantageous, as the engineered strains can be driven under the normal growth, 
Table 1 The primer pairs used in the PGASO construction

\begin{tabular}{|c|c|c|}
\hline \multirow{2}{*}{\multicolumn{2}{|c|}{$\begin{array}{l}\text { Primer name } \\
\text { Cassette construction }\end{array}$}} & Sequence \\
\hline & & \\
\hline \multirow[t]{2}{*}{ Lac4-KanMx } & Kl-PLac4-3'End-F & 5'-TAGGGCCTGTTTGGCCTCCCGCGGGGATC-3' \\
\hline & $\begin{array}{l}\text { KI-LAC4_-_Gap_Dra3_R } \\
\text { 46bpScPGap }\end{array}$ & 5'-TAGCACTCAGTGATTATTTACGTATTCTTTGAAATGGCAGTATTGATAATGATAAACTTATACAACATCGAAGAAGAGTC-3' \\
\hline \multirow{6}{*}{$\begin{array}{l}\text { ScGapDH- } \\
\text { Eglll }\end{array}$} & ScPGapDH-F-Bgll & 5'-TAGGCCATGACGGCAGTTTATCATTATCAATACTGCC-3' \\
\hline & AFEglll_ScPGapDH_R & 5'-GTAGAGAATTTCATTITITTGTTGTTTATGTGTGTTTAT -3' \\
\hline & ScPGapDH_AFEgllI_F & 5'-ATAAACACACATAAACAAACAAAAAAATGAAATTCTCTAC-3' \\
\hline & ScTTGap_Eglll_R & 5'-AAGATTTAAAGTAAATTCACGCGGCCGCCTACTTTCTTGCGAGACACG -3' \\
\hline & Eglll_ScTTGap_F & 5'-CGTGTCTCGCAAGAAAGTAGGCGGCCGCGTGAATTTACTTTAAATCTT-3' \\
\hline & $\begin{array}{l}\text { ScTTGap_Kl_- } \\
\text { PGapDH_R }\end{array}$ & 5'-CTTTTCCATTTGCCTTCGCGCTTGCCTGTACGGTCGTTACCATACTTGGCGGAAAAAATTCATTTG -3' \\
\hline \multirow{6}{*}{$\begin{array}{l}\text { KIGapDH- } \\
\text { CBHI }\end{array}$} & Kl-PGapDH-F & 5'-AGTATGGTAACGACCGTACAGGCAA-3' \\
\hline & AFCBHI_KIPGapDH_R & 5'-GTAGAGAATTTCATTTTTTTTGTGTAATATTCTTTTTTTT-3' \\
\hline & KIPGapDH_AFCBHI_F & 5'-AAAAAAAAGAATATTACACAAAAAAAATGAAATTCTCTAC -3' \\
\hline & ScTTGap_CBHI_R & 5'-AAGATTTAAAGTAAATTCACGCGGCCGCTTACAGGCACTGAGAGTAGT -3' \\
\hline & CBHI_ScTTGap_F & 5'-ACTACTCTCAGTGCCTGTAAGCGGCCGCGTGAATTTACTTTAAATCTT -3' \\
\hline & ScTTGap_KI_PADHI_R & 5'-TGGTAACGACCGTACAGGCAAGCGCGAAGGCAAATGGAAAAGCTGGTGGCGGAAAAAATTCATTTG-3' \\
\hline \multirow{4}{*}{$\begin{array}{l}\text { KIADHI- } \\
\text { GFP }\end{array}$} & KI-PADHI-F & 5'-CCAGCTTTCCATTTGCCTTCGCGCTTGCC-3' \\
\hline & GFPKLADHI-R & 5'-TCCTCGCCCTTGCTCACCATITTATCTIITITIAGTATAGAGT-3' \\
\hline & KLADHIGFP-F & 5'-ACTCTATACTAAAAAAAGATAAAATGGTGAGCAAGGGCGAGGA-3' \\
\hline & $\begin{array}{l}\text { ScTTGap_ } \\
\text { 46bpScPADHI_ } \\
\text { CGA-Bgll_R }\end{array}$ & 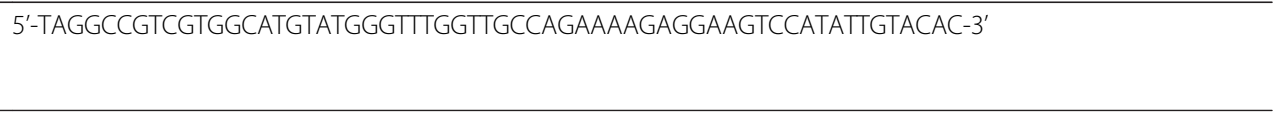 \\
\hline \multirow{4}{*}{$\begin{array}{l}\text { ScADHI- } \\
\text { NpaBGS }\end{array}$} & ScPADHI_CGA-Bgll_F & 5'-TAGGCCACGACGGCGTGTACAATATGGACTTCCTCTTTTC -3' \\
\hline & NpaBGS-Bgl|I-F & 5'-ACGAGATCTAAAAAAATGAAATTCTCT-3' \\
\hline & NpaBGS-Smal-R & 5'-TATCCCGGGTTAGTAAAGTTTGTAAGC-3' \\
\hline & Kl-PLac4 -5’End-R-Sfil & 5'-AGGGCCAAGAAGGCCAGCCGCGGAAATTTAGGAATTTTAAAC-3' \\
\hline
\end{tabular}

\begin{tabular}{|c|c|c|}
\hline \multicolumn{3}{|c|}{ Checking primer } \\
\hline \multirow[t]{2}{*}{ Kan } & Kan-Bglll-F & 5'-AAAAAGATCTGCCACCATGGGTAAGGAAAAGACTC-3' \\
\hline & Kan-Xbal-R & 5'-AAAAATCTAGATTAGAAAAACTCATCGAGCAT-3' \\
\hline \multirow[t]{2}{*}{ Eglll } & EgIII-1084 F & 5'-GACATGTGCCAGCAAATCCAATATC-3' \\
\hline & $\begin{array}{l}\text { ScTTGap_Kl_ } \\
\text { PGapDH_R }\end{array}$ & 5'CTTTCCATTTGCCTTCGCGCTTGCCTGTACGGTCGTTACCATACTTGGCGGAAAAAATTCATTTG-3' \\
\hline \multirow[t]{2}{*}{$\mathrm{CBHI}$} & KI-PGapDH-F & 5'-AGTATGGTAACGACCGTACAGGCAA-3' \\
\hline & $\mathrm{CBHI}-218 \mathrm{R}$ & 5'-AAGTGTTGCCATCGTAGCAGTTCGT-3' \\
\hline \multirow[t]{2}{*}{ GFP } & GFP-Bglll-F & 5'-ACGAGATCTATGGTGAGCAAGGGCGA-3' \\
\hline & GFP-Smal-R & 5'-TATCCCGGGTTACTTGTACAGCTCGTCCA-3' \\
\hline \multirow[t]{2}{*}{ NpaBGS } & NpaBGS-1422-F & 5'-TCCAGGTCCAGTTAATGTTCCATTC-3' \\
\hline & NpaBGS-Smal-R & 5'-TATCCCGGGTTAGTAAAGTTTGTAAGC-3' \\
\hline \multicolumn{3}{|c|}{ Internal primer } \\
\hline \multirow{3}{*}{$\begin{array}{l}\text { amplicon } \\
\text { L-K }\end{array}$} & Lac4-Primer1 & 5'-ACACACGTAAACGCGCTCGGT-3' \\
\hline & Kan-126R & 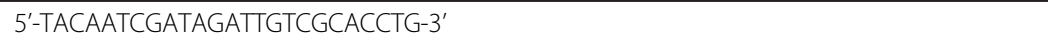 \\
\hline & Kan-673 F & 5'-CAGGATCTTGCCATCCTATGGAACT-3' \\
\hline $\begin{array}{l}\text { amplicon } \\
\text { K-E }\end{array}$ & Eglll-528R & 5'-TACTTGGAAATGCTCGTGGAATCAA-3' \\
\hline \multirow{2}{*}{$\begin{array}{l}\text { amplicon } \\
\text { E-C }\end{array}$} & EgIII-1084 F & 5'-GACATGTGCCAGCAAATCCAATATC-3' \\
\hline & $\mathrm{CBHI}-218 \mathrm{R}$ & 5'-AAGTGTTGCCATCGTAGCAGTTCGT-3' \\
\hline \multirow{2}{*}{$\begin{array}{l}\text { amplicon } \\
\text { C-G }\end{array}$} & CBHI-585 F & 5'-CGATCTGAAGTTCATCAATGGCCAG-3' \\
\hline & GFP-150R & 5'-GTGCAGATGAACTTCAGGGTCAGCT-3' \\
\hline
\end{tabular}


Table 1 The primer pairs used in the PGASO construction (Continued)

\begin{tabular}{|c|c|c|}
\hline amplicon & GFP-492 F & 5'-GAACTTCAAGATCCGCCACAACATC-3' \\
\hline & NpaBGS-403R & 5'-CACATTCACCAACATAGAATGGATC-3' \\
\hline amplicon N-L & NpaBGS $-1422 \mathrm{~F}$ & 5'-TCCAGGTCCAGTTAATGTTCCATTC-3' \\
\hline & Lac4-3'-436-R & 5'-ACTCTACATGCGACTTGGAAGGC-3' \\
\hline UPL system C & QPCR primer & \\
\hline Kan & Kan-UPL\#144 F & 5'- AGACTAAACTGGCTGACGGAAT-3' \\
\hline & Kan-UPL\#144R & 5'- CATCAGGAGTACGGATAAAATGC -3' \\
\hline Eglll & Eglll-UPL\#77 F & 5'- TGGCTCCGACAGAACAATC - $3^{\prime}$ \\
\hline & EgIII-UPL\#77R & 5'- GTCTTGTATGCAGGACTGAACG -3' \\
\hline $\mathrm{CBHI}$ & CBHI-UPL\#77 F & 5'- ACATCAAGTTCGGACCCATT-3' \\
\hline & $\overline{C B H I-U P L \# 77 R}$ & 5'- GGTAGGTCCGGGAGAGCTT-3' \\
\hline GFP & GFP-UPL\#148 F & 5'- TCTATATCATGGCCGACAAGC-3' \\
\hline & GFP-UPL\#148 F & 5'- GTTGTGGCGGATCTTGAAGT-3' \\
\hline NpaBGS & NpaBGS-UPL\#150 F & 5'- GAAGCTGTAATGGAAGAAGATGG-3' \\
\hline & NpaBGS-UPL\#150R & 5'- CTGGGAATGAAAGGAAAATCAT-3' \\
\hline Alg9 & ALG9-UPL\#151 F & 5'- GTGGGTCTATACCACGTCTCATC-3' \\
\hline Actin & ALG9-UPL\#151R & 5'- TCCAAATATAACGAATTTAAGCAACTT-3' \\
\hline & ACTIN-UPL \#9 F & 5'- GCGTAGATTGGAACAACGTG-3' \\
\hline & $\overline{A C T I N-U P L ~ \# 9 R ~}$ & 5'- AGAACTACCGGTATTGTGTTGGA-3' \\
\hline
\end{tabular}

on different carbon sources, or under a high cell density immobilization condition. Moreover, the wide spectrum of induction strengths observed in different promoters may be drawn upon to devise efficient gene expression systems for optimal enzyme-cocktails or to study gene regulation in yeast.

\section{Characterization of the secreted cellulases of KR5}

To quantify the secreted cellulase activities, the supernatant of KR5 was harvested for analysis without protein purification. The commercial cellulolytic enzyme mixture kits Celluclast $1.5 \mathrm{~L}$ and Novozyme 188 were used as the benchmarks; the supernatant with KR5 secreted cellulases and diluted commercial enzymes were estimated using an equal MUC activity which represented the total glucanase activity. The MUC activity assay was performed with MUC as the substrate, and the results indicated that the MUC activity in the supernatant of KR5 was equivalent to those of 0.5 unit of Celluclast 1.5 $\mathrm{L}$ and 1 unit of Novozyme 188, and higher than that of the control strain (Figure 4A). The glucose assay indicated significantly improved digestion of PASC by KR5; the activity was up to $80 \%$ of that of the 0.5 unit of Celluclast $1.5 \mathrm{~L}$ (Figure 4B). The activity assay with Dye$\mathrm{CMC}$ as the substrate suggested that the endo-glucanase activity in the supernatant was significantly improved due to the EGIII secreted by KR5; the activity was $60 \%$ of the 0.5 unit of Celluclast $1.5 \mathrm{~L}$ (Figure $4 \mathrm{C}$ ). The activity assay with pNPG as the substrate showed that the beta-glucosidase activity of NpaBGS in the supernatant of KR5 was higher than that of the control strain, and the activity was nearly $80 \%$ of the 1 unit of Novozyme 188 (Figure 4D). These data demonstrated successful coexpression of the exogenous fungal genes and secretion of their gene products without any significant posttranslational modification problems.

Successful protein production in a heterologous host at a commercial scale often requires the regulation of the timing and the expression level of the cloned gene (s). The long culturing-time required by fungi is a current bottleneck of traditional enzyme purification technologies, such as Celluclast $1.5 \mathrm{~L}$ from Trichoderma and Novo188 from Aspergillus. The faster growth rate of K. marxianus makes it more desirable for commercial enzyme production. In addition to efficient expression vectors and transformation protocols, heterologous gene expression also depends on a signal sequence to direct the secretion of the synthesized protein to the extracellular environment. In this study, we have used the promoters described above and the signal sequence of the $K$. lactis alpha-mating factor to express and secret the heterologous cellulases in KR5, at a much higher efficiency than the classical $S$. cerevisiae system. Furthermore, the new host strain K. marxianus KR5 is not only naturally competent to secrete enzymes, but also efficient for combining different enzyme systems for downstream processing of low-cost industrial enzymes.

\section{Sugar utilization and ethanol production assay}

Several types of cellulose were tested in this study to determine the carbon source utilization and ethanol fermentation abilities of KR5, KY3-NpaBGS, which is a 


\section{(A)}

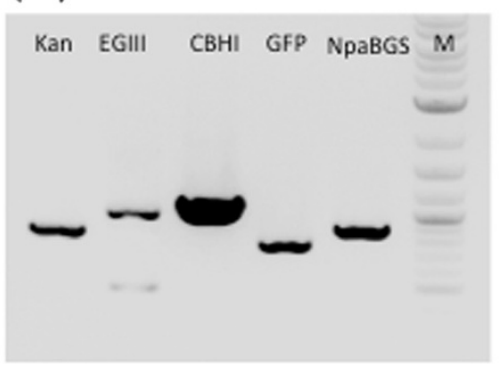

(C)

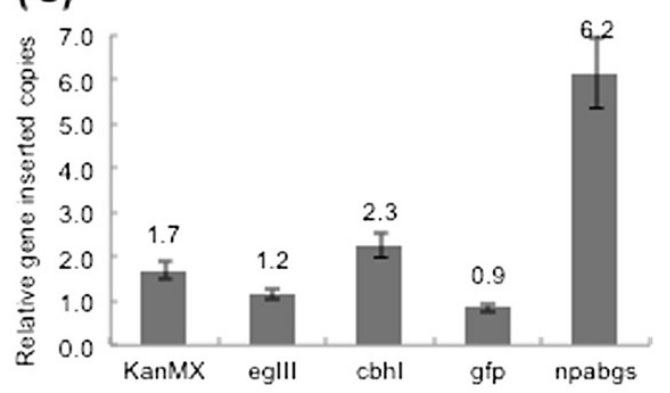

(B)

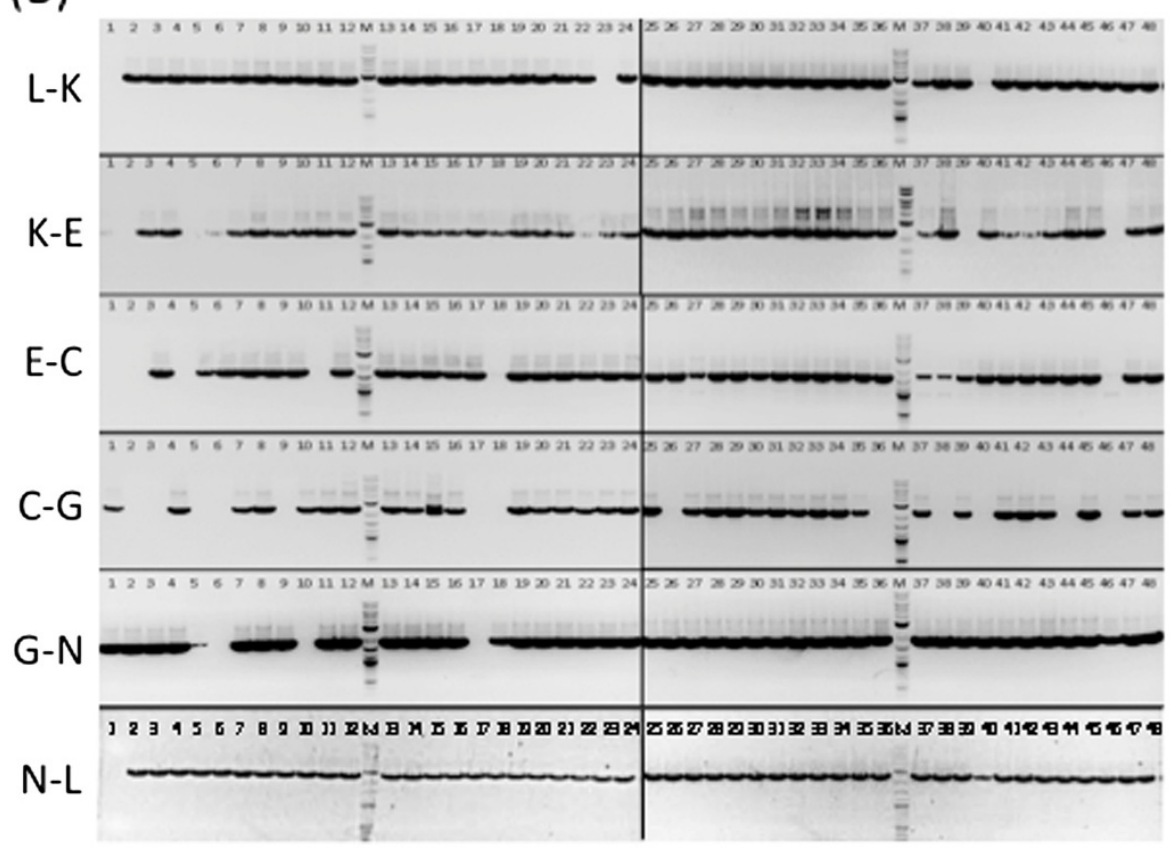

Figure 2 Gene insertion confirmation and copy-number quantification. (A) The five-gene insertion was confirmed by PCR with five pairs of gene specific internal primers. The PCR products revealed five specific bands: 810 bp (kan), 1012 bp (eglll), 1068 bp (cbhl), 750 bp (gfp), and 896 $\mathrm{bp}$ (NpaBGS). (B) The order of the gene cassettes was confirmed by PCR with five internal primer pairs. The PCR products resulted in six specific amplicons. (C) The relative ratios of the inserted gene copy numbers relative to the alg9 gene in KR5.

KY3 strain transformed with the NpaBGS gene, and the control strain NC. All three strains are capable of utilizing glucose and cellobiose for growth, and KY3-NpaBGS can grow on beta-glycan substrate, but only KR5 can significant assimilate beta-glycan and CMC (Figure 5A). To examine the SSF ability of KR5, fermentation was performed in the YP medium containing cellobiose, betaglycan, CMC or PASC as the sole carbon source. After cultivation of cells in YPD medium for $24 \mathrm{~h}$ at $30^{\circ} \mathrm{C}$, the cells, which had an O.D. of 20, were harvested for subsequent inoculum. As shown in Fig. 5, KR5 could use cellobiose, beta-glycan, CMC or PASC as the sole carbon source for fermentation. When cellobiose was used as the carbon source, KR5 produced $8.5 \mathrm{~g} / \mathrm{L}$ ethanol with a $93 \%$ conversion ratio in $168 \mathrm{~h}$ at $37^{\circ} \mathrm{C}$ (Figure 5A). This efficiency of cellobiose utilization is as good as its glucose utilization, When $2 \%$ beta-glycan was the sole carbon source, KR5 produced $5.4 \mathrm{~g} / \mathrm{L}$ ethanol with a $74 \%$ conversion ratio in $168 \mathrm{~h}$ at $37^{\circ} \mathrm{C}$ (Figure $5 \mathrm{~B}$ ). These data indicated that KR5 could express cellulolytic enzymes and directly produce ethanol from cellulosic materials. The CMC and PASC assimilation abilities were only moderately increased compared to the control strain (Figure 5C). However, it is unclear why KR5 could not efficiently produce ethanol from CMC and PASC. Prior research reported that $K$. marxianus might not utilize carboxymethyl glucose, which is released from carboxymethyl cellulose and may inhibit cell growth [29]. It has been reported that while $K$. marxianus could be transformed with different cellulase genes, a higher 


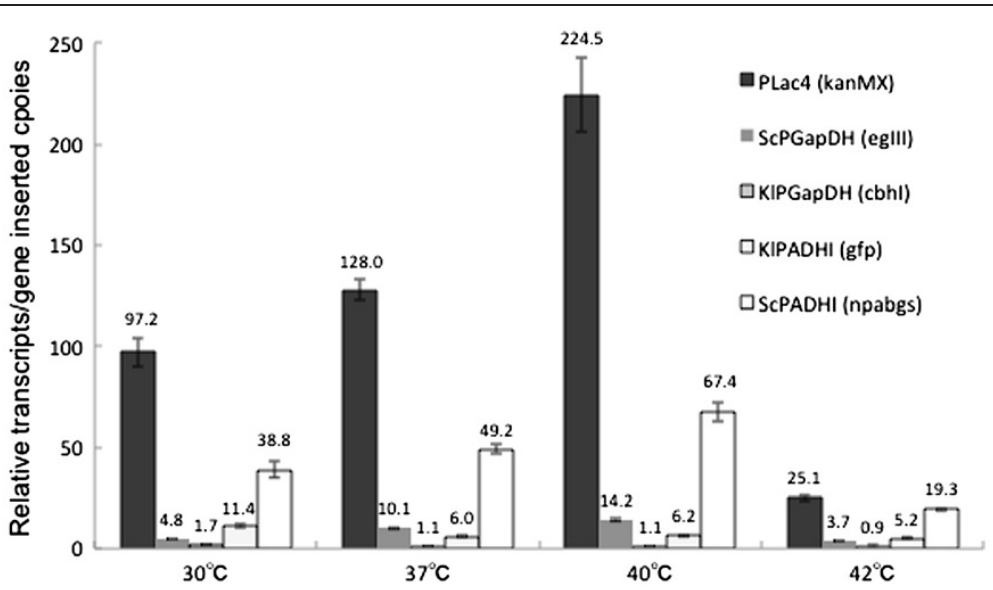

Figure 3 The quantitative PCR analysis of the five gene cassettes in KR5. The relative ratios of the five promoter transcripts are shown in comparison to the alg9 gene in KR5 at different temperatures. These ratios are normalized by the respective gene cassette insertion copy number estimates.

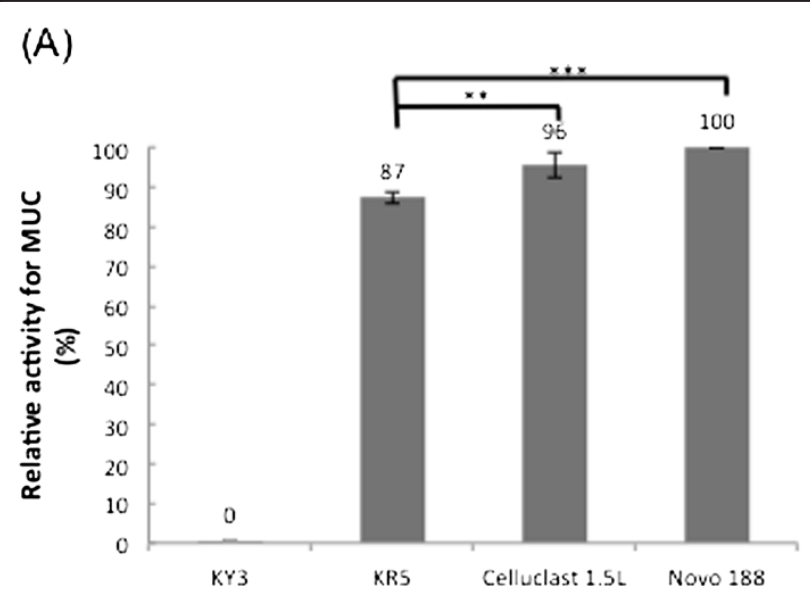

(C)

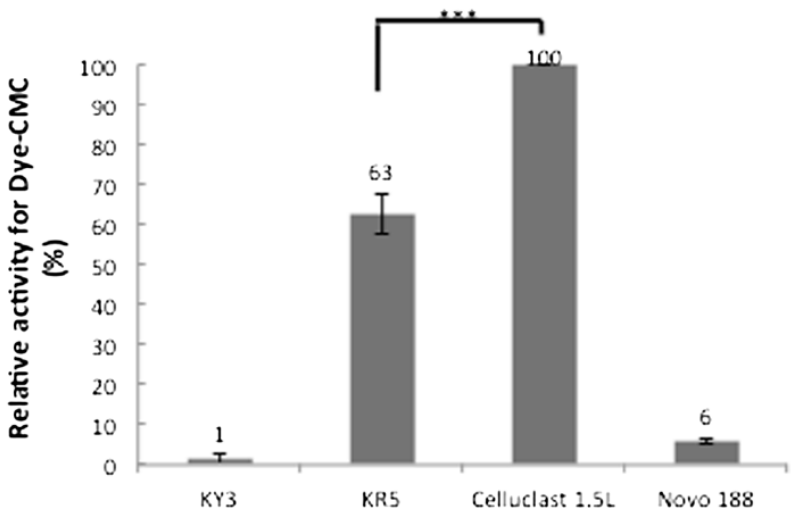

(B)

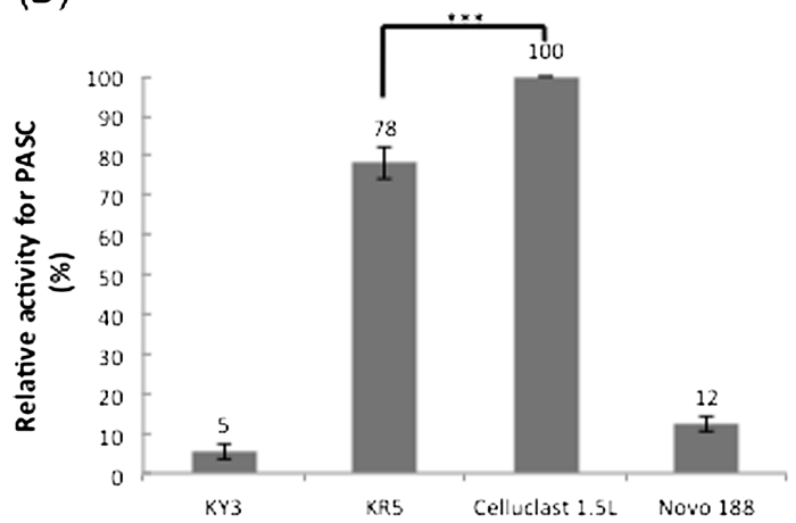

(D)

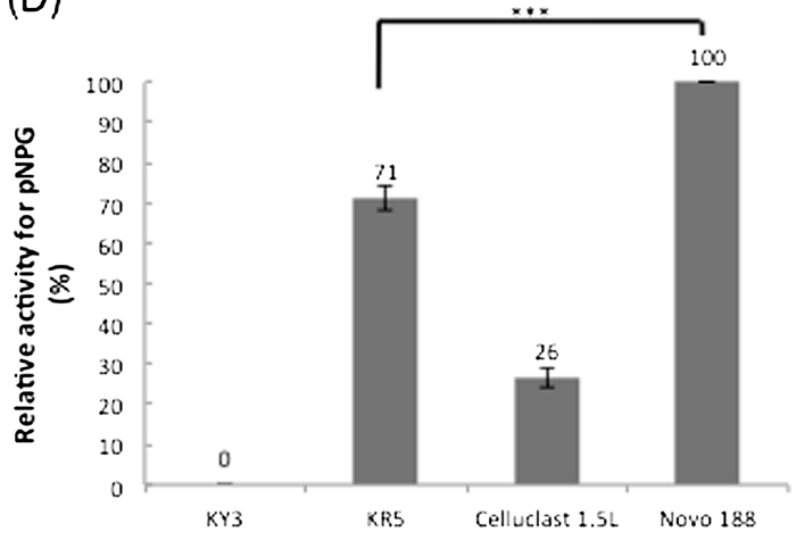

Figure 4 Cellulolytic enzyme assays of $K$. marxianustransformants. The relative activities were conducted using (A) MUC, (B) Dye-CMC, (C) PASC, and (D) pNPG as the substrate, respectively. The commercial cellulolytic enzyme mixture kits with 0.5 unitCelluclast $1.5 \mathrm{~L}$ and 1 unit Novozyme 188 were used as benchmarks. The protein concentration of the supernatant of the $K$. marxianus transformants cultures were $1.3 \mathrm{mg} / \mathrm{ml}$. *: $\mathrm{P}<0.05$ (significant), **: $\mathrm{P}<0.01$; **: $\mathrm{P}<0.001$; N.S., non-significant. 


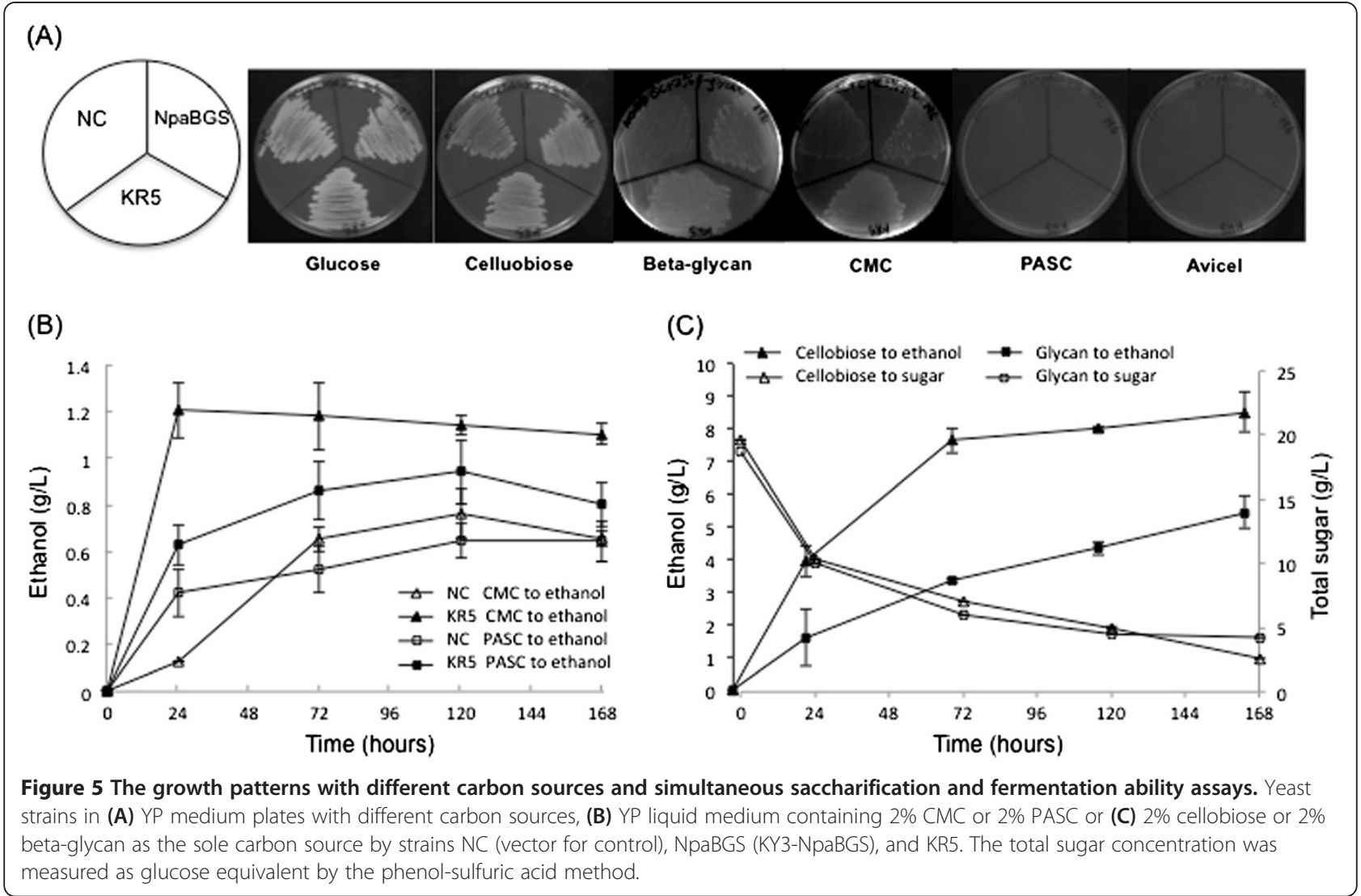

endoglucanase enzyme expression level than other enzymes could be critical for cellulolytic reactions $[30,31]$. Therefore, in future work we will construct new KY3 strains that can efficiently convert cellulose into component sugars by integrating more cellulolytic genes and by optimizing multiple gene expression ratios via the PGASO method.

$K$. marxianus has a number of advantages, such as heat and toxin tolerance, over the model organisms $K$. lactis and S. cerevisiae [5]. PGASO can be applied to facilitate enzyme combinations or to construct desired pathways in $K$. marxianus KY3. The wide spectrum of induction strengths observed in different promoters may be drawn upon to devise efficient gene expression systems for optimal enzyme-cocktails or to study gene regulation in yeast. Furthermore, PGASO is potentially applicable to any host that can undergo homologous recombination. The potential to control the expression ratios of different enzymes is a sought-after feature for many applications. Our study has demonstrated a success in the development of this yeast strain as a new host for heterologous protein production and as a cell factory for enzyme production.

\section{Conclusion}

Our use of the specific 5'-upstream region of the promoter as the specific homologous recombination sites, requiring no linkers, is the first such application in a yeast other than $S$. cerevisiae. In this study, we have developed a new synthetic biology tool, PGASO, and used it to engineer a new yeast host, KR5, to express three types of highly efficient cellulases for biomass conversion. KR5 showed a significant improvement in lignocellulosic polysaccharide utilization and ethanol conversion. Our study demonstrated a successful development of this yeast strain as a new host for heterologous protein production and as a cell factory for enzyme production. It also showed that $K$. marxianus KY3 is a good host for multi-gene assembly and genome engineering via the synthetic biology approach. The potential of PGASO to control the expression ratios of different enzymes is a sought-after feature for many applications.

\section{Methods}

\section{Multiple-gene cassette construction}

An application of PGASO to assemble five gene cassettes in a predesignated order is illustrated in Figure 1. In the first gene cassette, the KanMX gene and the Lac4 promoter fragment from pKlac2 vector (K. lactis Protein Expression Kit, New England Biolabs) were amplified and assembled into a fragment with the Lac4-KanMX primer pairs. The coding regions of the second and the 
third gene cassettes, the EGIII gene and the CBHI gene, were amplified from the cDNA of $T$. reesei and assembled with the ScGapDH promoter and KIPADHI promoter region by the ScGapDH-EgIII and the KlGapDH-CBHI primer pairs via fusion PCR, respectively. The fourth gene cassette with the gfp gene was constructed using the KlADHI-GFP primer pairs. The fifth gene cassette with the NpaBGS gene [28] and a ScADHI promoter were respectively amplified and constructed using the ScADHI-NpaBGS primer pairs. Consecutive gene cassettes containing overlapping $46 \mathrm{bp}$ regions on the border are used for recombinatorial gene assembly. The PCR to check the assembly was conducted using the TaKaRa Ex Taq system and the primer pairs used are listed in Table 1 . The reaction mixture contained $0.2 \mathrm{mM}$ of each primer, $0.25 \mathrm{mM}$ of each deoxynucleoside triphosphate, $1 \mathrm{x}$ PCR buffer with $2 \mathrm{mM}$ $\mathrm{MgCl}_{2}, 2 \mu \mathrm{L}$ of DNA and $2.5 \mathrm{U}$ of Ex Taq DNA polymerase. PCR reaction was carried out at $94^{\circ} \mathrm{C}$ for $1 \mathrm{~min}$, touchdown annealing temperature from $58^{\circ} \mathrm{C}$ to $53^{\circ} \mathrm{C}$ for $1 \mathrm{~min}$, and $72^{\circ} \mathrm{C}$ for optimized period for 10 cycles.

\section{Yeast transformation and clone screening}

The cells were incubated in $5 \mathrm{ml}$ YPD medium (1\% BactoDifco-Yeast Extract, 2\% BactoDifco-Peptone, 2\% Merck-D(+)-Glucose) at $30^{\circ} \mathrm{C}$, shaking at $200 \mathrm{rpm}$ for 16 $\mathrm{hr}$. To express heterologous enzymes in KY3, we followed the transformation method for $K$. lactis (Sánchez et al., 1993). The target DNA fragments in a $5 \mu \mathrm{g}$ volume with an equal molar ratio of each fragment were mixed with 40 $\mu \mathrm{l}$ of competent cells. The electroporation was performed (1.0 kV, $400 \Omega$, and $25 \mu \mathrm{F}$ capacitance) using a BioRad system (GenePluserXcell TM, Bio-Rad, Hercules, CA) with an aluminum cuvette $(2 \mathrm{~mm})$. The cells were spread onto YPG plates (1\% BactoDifco-Yeast Extract, 2\% BactoDifcoPeptone, and 2\% Merck-galactose) containing G418 (200 $\mu \mathrm{g} / \mathrm{mL}$ ). To confirm the presence of each fragment, each isolated colony was digested in QucikExtract ${ }^{\mathrm{TM}}$ DNA Extraction Solution (EPICENTRE, Madison, Wisconsin) to remove yeast cell wall and was then examined by PCR with gene specific checking primers (Table 1). Moreover, to verify that these gene cassettes were inserted into the correct position of the KR5 genome and assembled in the correct order, specific internal primer pairs of gaps of each cassette were designed and confirmed by PCR (Table 1). These clones were further examined under a bright field microscope with phase contrast and fluorescence with a GFP filter, and photographed by a confocal microscope and single molecule detection system (Leica TCS-SP5MP-SMD, Germany).

\section{Quantitative PCR analysis}

The cells of each isolate were incubated at $30^{\circ} \mathrm{C}, 37^{\circ} \mathrm{C}$, $40^{\circ} \mathrm{C}$, and $42^{\circ} \mathrm{C}$ with $200 \mathrm{rpm}$ for $16 \mathrm{hr}$. The genomic
DNA was purified from yeast cells using a DNA Isolation Kit III (DNA Isolation Kit III, Roche). The template mRNA was each purified from yeast cells using RNeasy Protect mini kits (High Pure RNA Isolation Kit, Roche). The cDNA synthesis was conducted using a reverse transcription kit (SuperScript ${ }^{\mathrm{TM}}$ II kit, Invitrogen). The relative quantification of each gene was carried out via the Universal Probe Library Set (LightCycler ${ }^{\circledR} 480$ Probes Master, Roche) with a specific primer pair (the amplicon size was 100 to $150 \mathrm{bp)}$ on a LightCycler (LightCycler 480, Roche), following the protocol of the manufacturer. Both actin and alg9 were employed as reference genes for quantitative PCR analysis. Standard curves were generated for each primer pair to estimate their amplification efficiency using the LightCycler software (LightCycler 480, Roche), and the quantitative PCR data were accordingly adjusted for use in subsequent analysis. The theoretical amplification efficiency is 2.0 , and the actual amplification efficiencies of the different primer pairs were 1.97 (gfp), 1.89 (npabgs), 1.98(actin), 1.93 (alg9), 1.94 (egIII), 1.98 (cbhI), and 1.98 (kan).

\section{Quantitative assays of enzyme activity}

The supernatants collected from yeast cultures were prepared for cellulase activity assays. The commercial cellulolytic enzyme mixture kits of 0.5 unit Celluclast $1.5 \mathrm{~L}$ (Novozyme, Denmark) and 1 unit Novozyme 188 (Novozyme, Denmark) were used as benchmarks. The commercial and yeast produced enzymes were assayed at the same MUC activity at $30^{\circ} \mathrm{C}$ with different protein concentrations, such as Celluclast $1.5 \mathrm{~L}(0.03 \mathrm{mg} / \mathrm{ml})$, Novozyme $188(0.85 \mathrm{mg} / \mathrm{ml})$, and supernatant of yeast culture $(1.3 \mathrm{mg} / \mathrm{ml})$. The total glucanase activity was assayed by adding $40 \mu \mathrm{l}$ of supernatant to final $100 \mu \mathrm{l}$ of buffer solution $(0.8 \mathrm{mg} / \mathrm{ml} \mathrm{4-methylumbelliferyl-} \beta$-D-cellobiopyranoside (MUC), $0.05 \mathrm{M}$ sodium acetate, $\mathrm{pH} 4.5$ ) at $30^{\circ} \mathrm{C}$ for $1 \mathrm{hr}$. The enzyme activity of released 4methylumbelliferone (MU) was measured in fluorescence units (FU) by the fluorescent intensity reader (SpectraMax M2, MDS) with excitation and emission wavelengths at $365 \mathrm{~nm}$ and $465 \mathrm{~nm}$. The relative activity of phosphoric acid-swollen cellulose (PASC) digestion was assayed by mixing $40 \mu \mathrm{l}$ of supernatant with $60 \mu \mathrm{l}$ of buffer solution containing $0.4 \%$ PASC. Both of them were reacted in the $0.05 \mathrm{M}$ sodium acetate, $\mathrm{pH} 4.5$ at $30^{\circ} \mathrm{C}, 24 \mathrm{hrs}$. After the hydrolysis reaction, the amount of reducing sugar was measured using the Somogyi-Nelson method to determine the number of glucose equivalents [32]. The relative activity of endo-glucanase was assayed by mixing $40 \mu \mathrm{l}$ of supernatant with $60 \mu \mathrm{l}$ of buffer solution containing $\quad 0.4 \% \quad(w / v) \quad$ Azo-CM-Cellulose (Dye-CMC) (Megazyme, Wicklow, Ireland) at $30^{\circ} \mathrm{C}, 6 \mathrm{hrs}$, and the detection was done via absorption of $590 \mathrm{~nm}$. To quantify the $\beta$-glucosidase activity, $10 \mu \mathrm{L}$ of the yeast 
culture supernatant was added to deep-well microtiter plates with each well containing $90 \mu \mathrm{L}$ of $50 \mathrm{mM}$ p-nitrophenyl- $\beta$-D-glucopyranoside (pNPG) (Sigma-Aldrich, St Louis, MO, USA), $0.05 \mathrm{M}$ acetate buffer $\mathrm{pH}$ 5.0, at $30^{\circ} \mathrm{C}, 10$ mins. The detection was done by the fluorescent intensity reader with absorbance at $410 \mathrm{~nm}$. The protein concentration was determined by the Bradford method.

\section{Carbon source utilization and ethanol production assay}

The transformed yeast cells were grown on $2 \%$ agar YP medium plates with cellobiose, $\beta$-glycan, CMC, or PASC as the single carbon source. This recipe in liquid medium was also used for yeast growth and ethanol fermentation. The semi-anarobic batch culturing was conducted in a $15 \mathrm{ml}$ serum tube with $5 \mathrm{ml}$ of medium with $10 \mathrm{ml}$ of air in the bottle at $37^{\circ} \mathrm{C}, 120 \mathrm{rpm}$ rolling. The initial inoculated cell density for each sample had an $\mathrm{O}$. D. of 20 at a wavelength of $600 \mathrm{~nm}$ using a spectrophotometer (Ultrospec 2100 pro; Amersham Bioscience). Total sugar concentration was measured as glucose equivalent by the phenol-sulfuric acid method [29]. The productivity of ethanol was analyzed by gas chromatography (Shimazdu, GC-14, Japan) with a flame ionization detector (FID) and a stainless steel column (80/120 Carbopack B/6.6\% Carbowax, $2 \mathrm{~m} \times 2 \mathrm{~mm}$ ), with nitrogen as mobile gas. The running condition included heating of the column from 80 to $150^{\circ} \mathrm{C}$ at a ramp rate of $4^{\circ} \mathrm{C}$ per min, an injection temperature of $180^{\circ} \mathrm{C}$, and a detection temperature of $250^{\circ} \mathrm{C}$. Each fermentation experiment and the subsequent analysis were repeated three times.

\section{Abbreviations}

PGASO: Promoter-based Gene Assembly and Simultaneous Overexpression; CBP: Consolidated bioprocessing; MUC: 4-methylumbelliferyl- $\beta$-Dcellobiopyranoside; PASC: Phosphoric acid-swollen cellulose; CMC: Carboxymethyl cellulose; Dye-CMC: Azo-CM-Cellulose; pNPG: p-nitrophenyl- $\beta$-D-glucopyranoside.

\section{Competing interests}

The authors declare that they have no competing interests.

\section{Authors' contributions}

$J-J C$ and $C-Y H$ designed experiments. J-JC, C-YH, F-JH, T-YT, H-MK, H-LC, and $\mathrm{CH}-\mathrm{TW}$ carried out the experiments, analyzed the data and drafted the manuscript. W-HL, C-CH and M-CS supervised the study. W-HL and C-CH revised the manuscript. All authors read and approved the final manuscript.

\section{Acknowledgments}

This work was supported by Academia Sinica, Taiwan and by the grants (NSC 96-3114-P-001-004-Y, NSC 97-3114-P-001-001, NSC 99-3113-B-001-001, NSC 100-3111-Y001-006, and NSC 99-2321-B-001-041-MY2) from the National Science Council and the ATU plan of the Ministry of Education, Taiwan. We thank the three anonymous reviewers for valuable comments and suggestions. We appreciate the valuable technical advice of Profs. Kenji Tsuge and Mitsuhiro Itaya and we thank Kevin Bullaughey for editing the manuscript.

\section{Author details}

'Biodiversity Research Center, Academia Sinica, Taipei 115, Taiwan. ${ }^{2}$ Genomics Research Center, Academia Sinica, Taipei 115, Taiwan. ${ }^{3}$ Department of Life Sciences, National Chung Hsing University, Taichung 402, Taiwan. ${ }^{4}$ Biotechnology Center, National Chung Hsing University, Taichung 115, Taiwan. ${ }^{5}$ Microbial Genomics, National Chung Hsing University, Taichung 402, Taiwan. ${ }^{6}$ Agricultural Biotechnology Research Center, Academia Sinica, Taipei 115, Taiwan. ${ }^{7}$ Department of Ecology and Evolution, University of Chicago, Chicago, IL 60637, USA.

Received: 6 April 2012 Accepted: 28 June 2012

Published: 27 July 2012

\section{References}

1. Lynd LR, van Zyl WH, McBride JE, Laser M: Consolidated bioprocessing of cellulosic biomass: an update. CurrOpinBiotechnol 2005, 16:577-583.

2. Ilmén M, den Haan R, Brevnova E, McBride J, Wiswall E, Froehlich A, Koivula A, Voutilainen SP, Siika-Aho M, la Grange DC, Thorngren N, Ahlgren S, Mellon M, Deleault K, Rajgarhia V, van Zyl WH, Penttilä M: High level secretion of cellobiohydrolases bySaccharomyces cerevisiae. Biotechnol Biofuels. 2011, 4:30.

3. Yamada R, Taniguchi N, Tanaka T, Ogino C, Fukuda H, Kondo A: Direct ethanol production from cellulosic materials using a diploid strain ofSaccharomyces cerevisiaewith optimized cellulase expression. Biotechnol Biofuels 2011, 4:8.

4. Nonklang S, Abdel-Banat BM, Cha-aim K, Moonjai N, Hoshida H, Limtong S, Yamada M, Akada R: High-temperature ethanol fermentation and transformation with linear DNA in the thermotolerant yeastKluyveromycesmarxianusDMKU3-1042. Appl Environ Microbiol 2008, 74:7514-7521.

5. Fonseca GG, Heinzle E, Wittmann C, Gombert AK: The yeastKluyveromycesmarxianusand its biotechnological potential. App/MicrobiolBiotechnol 2008, 79:339-354.

6. Sánchez M, Iglesias FJ, Santamaría C, Domínguez A: Transformation ofKluyveromyceslactisby Electroporation. Appl Environ Microbiol 1993, 59:2087-2092.

7. van Ooyen AJ, Dekker P, Huang M, Olsthoorn MM, Jacobs DI, Colussi PA, Taron $\mathrm{CH}$ : Heterologous protein production in the yeastKluyveromyceslactis. FEMS Yeast Res 2006, 6:381-392.

8. Liu Q, Li MZ, Leibham D, Cortez D, Elledge SJ: The univector plasmidfusion system, a method for rapid construction of recombinant DNA without restriction enzymes. CurrBiol 1998, 8:1300-1309.

9. Shuldiner AR, Scott LA, Roth J: PCR-induced (ligase-free) subcloning: a rapid reliable method to subclone polymerase chain reaction (PCR) products. Nucleic Acids Res 1920, 1990:18.

10. Aslanidis C, de Jong PJ: Ligation-independent cloning of PCR products (LIC-PCR). Nucleic Acids Res 1990, 18:6069-6074.

11. Hartley JL, Temple GF, Brasch MA: DNA cloning using in vitro site-specific recombination. Genome Res 2000, 10:1788-1795.

12. Walhout AJ, Temple GF, Brasch MA, Hartley JL, Lorson MA, van den Heuvel S, Vidal M: GATEWAY recombinational cloning: application to the cloning of large numbers of open reading frames or ORFeomes. Methods Enzymol 2000, 328:575-592.

13. Pachuk CJ, Samuel M, Zurawski JA, Snyder L, Phillips P, Satishchandran C Chain reaction cloning: a one-step method for directional ligation of multiple DNA fragments. Gene 2000, 243:19-25.

14. Tsuge $K$, Matsui K, Itaya M: One step assembly of multiple DNA fragments with a designed order and orientation inBacillus subtilisplasmid. Nucleic Acids Res 2003, 31:e133.

15. Shao Z, Zhao H: DNA assembler, an in vivo genetic method for rapid construction of biochemical pathways. Nucleic Acids Res 2009, 37:e16.

16. Bitinaite J, Rubino M, Varma KH, Schildkraut I, Vaisvila R, Vaiskunaite R: USER friendly DNA engineering and cloning method by uracil excision. Nucleic Acids Res 2007, 35:1992-2002.

17. Li MZ, Elledge SJ: MAGIC, an in vivo genetic method for the rapid construction of recombinant DNA molecules. Nat Genet 2005, 37:311-319.

18. Li MZ, Elledge SJ: Harnessing homologous recombination in vitro to generate recombinant DNA via SLIC. Nat Methods 2007, 4:251-256.

19. Marsischky G, LaBaer J: Many paths to many clones: a comparative look at high-throughput cloning methods. Genome Res 2004, 14:2020-2028. 
20. Kegel A, Martinez P, Carter SD, Astrom SU: Genome wide distribution of illegitimate recombination events inKluyveromyceslactis. Nucleic Acids Res 2006, 34:1633-1645.

21. Quan J, Tian J: Circular polymerase extension cloning of complex gene libraries and pathways. PLoS One 2009, 4:e6441.

22. Gibson DG, Benders GA, Axelrod KC, Zaveri J, Algire MA, Moodie M, Montague MG, Venter JC, Smith HO, Hutchison CA 3rd: One-step assembly in yeast of 25 overlapping DNA fragments to form a complete synthetic Mycoplasma genitalium genome. ProcNat/AcadSCi USA 2008, 105:20404-20409.

23. Gibson DG, Young L, Chuang RY, Venter JC, Hutchison CA 3rd: Smith HO: Enzymatic assembly of DNA molecules up to several hundred kilobases. Nat Methods 2009, 6:343-345.

24. Beggs JD: Transformation of yeast by a replicating hybrid plasmid. Nature 1978, 275:104-109.

25. Gietz RD, Woods RA: Transformation of yeast by lithium acetate/singlestranded carrier DNA/polyethylene glycol method. Methods Enzymol 2002, 350:87-96.

26. Das S, Hollenberg CP: A high-frequency transformation system for the yeast Kluyveromyceslactis. Curr Genet 1982, 6:123-128.

27. Abdel-Banat BM, Nonklang S, Hoshida H, Akada R: Random and targeted gene integrations through the control of non-homologous end joining in the yeastKluyveromycesmarxianus. Yeast 2010, 27:29-39.

28. Chen HL, Lu MY, Chen YC, Chang JJ, Wang HT, Wang TY, Ruan SK, Wang TY, Hung KY, Cho HY, Ke HM, Lin WT, Shih MC, Li WH: A highly efficient $\beta$ glucosidase from the calf lumen fungusNeocallimastixpatriciarumW5. Biotechnol Biofuels 2012, in press.

29. Rasmussen MA, Hespell RB, White BA, Bothast RJ: Inhibitory Effects of Methylcellulose on Cellulose Degradation by Ruminococcusflavefaciens. Appl Environ Microbiol 1988, 54:890-897.

30. Hong J, Wang Y, Kumagai H, Tamaki H: Construction of thermotolerant yeast expressing thermostablecellulase genes. J Biotechnol 2007, 130:114-123.

31. Yanase S, Hasunuma T, Yamada R, Tanaka T, Ogino C, Fukuda H, Kondo A: Direct ethanol production from cellulosic materials at high temperature using the thermotolerant yeastKluyveromycesmarxianusdisplaying cellulolytic enzymes. App/Microbio/Biotechnol 2010, 88:381-388.

32. Dubois M, Gilles KA, Hamilton JK, Rebers PA, Smith F: Colorimetric method for determination of sugars and related substances. Anal Chem 1956, 28:350-356.

doi:10.1186/1754-6834-5-53

Cite this article as: Chang et al.: PGASO: A synthetic biology tool for engineering a cellulolytic yeast. Biotechnology for Biofuels 2012 5:53.

\section{Submit your next manuscript to BioMed Central and take full advantage of:}

- Convenient online submission

- Thorough peer review

- No space constraints or color figure charges

- Immediate publication on acceptance

- Inclusion in PubMed, CAS, Scopus and Google Scholar

- Research which is freely available for redistribution

Submit your manuscript at www.biomedcentral.com/submit 